\title{
Bacteria profile and antibiogram of the bacteria isolated from the exposed pulp of dog canine teeth
}

J. C. Almansa Ruiz, A. Jonker, A-M. Bosman, G. Steenkamp.

J. C. Almansa Ruiz, DrVetMed (Hons), MSc (Vet), G. Steenkamp, BSc, BVSc, MSc, PhD (Zool.), Department of Companion Animal Clinical Studies, Faculty of Veterinary Science, University of Pretoria, Onderstepoort, Pretoria, South Africa. Private Bag X04; 0110.

A. Jonker, BVSc MSc, A-M. Bosman, BSc, MSc, Department of Tropical Diseases, Faculty of Veterinary Science, University of Pretoria, Onderstepoort, Pretoria, South Africa. Private Bag X04; 0110.

This manuscript represents a portion of a thesis submitted by J.C. Almansa Ruiz to the University of Pretoria, Department of Companion Animal Clinical Studies as partial fulfillment of the requirements for a Master of Science degree.

The research was funded by The Peter Emily International Veterinary Dental Foundation, Department of Companion Animal Clinical Studies of the University of Pretoria and the University of Pretoria Research Fund.

E-mail for correspondence: jcalmansa.vet@gmail.com 


\begin{abstract}
Twenty-seven microbiological samples were taken from root canals (RC) of the canine teeth of 20 dogs where the pulps were nonvital and exposed due to complicated crown fractures (CCF). These pulps were cultured for aerobic / anaerobic bacteria. Antimicrobial susceptibility of isolates was determined using the Kirby-Bauer diffusion test. A total of 49 cultivable isolates, belonging to 27 different microbial species and 18 different genera were recovered from the $27 \mathrm{RC}$ sampled. Twenty $(40.81 \%)$ of the cultivable isolates were Gram positive while $29(59.19 \%)$ were Gram negative. Facultative anaerobes were the most common bacteria (77.56\%). Aerobic isolates represented $18.36 \%$, and strict anaerobes $4.08 \%$. The antimicrobials with the highest in vitro efficacy were gentamicin (100\%), and enrofloxacin $(93.32 \%)$
\end{abstract}

\title{
1. Introduction
}

Clinical endodontics comprises several techniques of which standard root canal therapy of pulps and root canal (RC) systems (with or without periradicular pathosis of pulpal origin) is the most important, in order for patients to retain their natural dental function (Peters and Peters 2011). Infection of the RC and other microbial dental diseases, such as periodontal disease, differ in the way infection establishes itself (Marsh 2003). The infection in the $\mathrm{RC}$ is unique, as it arises in a location where microorganisms have not previously been present, compared with other major dental diseases where the infection develops from a well established biofilm added to changes in the environment and to the microbial flora (Marsh 2003). The role of microbes and their antimicrobial susceptibilities in both acute and chronic infections of the dental pulp in humans has been well studied (Gomes 1995; Jacinto and others 2003; Lana and others 2001; Siqueira and Rocas 2008; Sundqvist and others 1998; Yoshida and others 1987). To date, only one similar study has been published on dogs 
(Ferreira and others 2006). It is also important to note that animals have different tooth anatomy and resident oral microflora compared to those of humans.

When RCT is performed under aseptic conditions and using recognised clinical principles, the success rate is high. Follow-up studies in humans on endodontic therapy reports a success rate ranging between $85 \%$ and $90 \%$ (Molven and Halse 1988; Sjogren and others 1990); meanwhile in veterinary dentistry this success is slightly higher at $95 \%$ (KuntsiVaattovaara and others 2002). In those human cases which fail to respond to treatment, technical problems arising during treatment, such as operator technique or inappropriate immunologic response are often blamed (Preshaw and others 2004). In veterinary dentistry, the evidence of a pre-operative periapical lucency, pulp necrosis, root resorption and which tooth was treated all have been reported as factors that decrease the success rate when performing non-surgical RCT (Kuntsi-Vaattovaara and others 2002). According to the literature in human endodontics, microorganisms persisting in the apical parts of RCs of obturated teeth are responsible for the majority of treatment failures (Nair and others 1990). $\mathrm{RC}$ infections can progress to systemic infections characterised by fever, lymphadenopathy, and/or fascial space involvement, as well as serum biochemistry changes, such as elevated serum cytokines and acute phase proteins (Hsiao and others 2012).

Complicated crown factures (CCF), involving enamel, dentin, and pulp (Sigurdsson and others 2011) of canine teeth is one of the most common dental conditions in military dogs (Le Brench and others 1997). Treatment of pulpal infections in dogs is limited as there is very little knowledge on the nature of the endodontic microflora as well as on their antimicrobial susceptibility. The aim of this study is to isolate and identify bacteria found in the RCs of dog canine teeth that suffering $\mathrm{CCF}$ and showing signs consistent with nonvital pulps. 
Furthermore, the bacteria isolated from these sampled RCs were tested against a panel of antimicrobials, in order to determine their efficacy in vitro.

\section{Materials and Methods}

\subsection{Patient selection}

Only patients with CCFs, of which the pulps were nonvital and that did not receive antibiotics for at least 2 weeks prior to presentation were included in this study. A tooth was deemed to have a nonvital pulp when no haemorrhage was observed during the sampling procedure. Dogs included in this study were either working dogs or ordinary pets. These were presented to the Dental and Maxillofacial Surgery Clinic of the Onderstepoort Veterinary Academic Hospital (OVAH), University of Pretoria, South Africa. For each dog, the owner's name, the patient's sex, age, diet, weight, dental record, and specific breed were recorded on a dental record sheet. The study was approved by the Animal Use and Care Committee, and the Research Committee of the University of Pretoria (V061/10).

\subsection{Sampling}

All dogs underwent a clinical examination, and blood smear. This last diagnostic test was performed to check for blood parasites and adequate platelet levels. Once patients were anaesthetised, they were positioned in lateral recumbency, with the affected canine tooth uppermost. An oral evaluation was performed and recorded on a dental record sheet before sampling. No rubber dam or tooth isolation devices were used in the sampling protocol. The RC was first opened through the fracture site using a sterile ISO 25 - 40 Hedström or Kerrfile $^{\mathrm{a}}$. In RC with nonvital pulp the material present is often desicated and therefore 2 to 3 drops of sterile lactated Ringers' solution ${ }^{\mathrm{b}}$ were placed on the file, while in the $\mathrm{RC}$, and filing of the RC was then performed until working length was reached. This addition of sterile 
lactated Ringer's solution was done in order to place the bacteria present in suspension. Larger files, ISO size 45 to 70 in size ${ }^{a}$, were required in RC of dogs younger than 3 years of age in order to also file the dentinal wall and remove dentin at risk for harbouring bacteria. A sterile paper point size ISO $25^{\mathrm{a}}$ was introduced into the $\mathrm{RC}$ at the maximum depth possible using dressing forceps whose active part had been first sterilised in a bead steriliser ${ }^{\mathrm{c}}$ for 30 seconds. The paper point was left in the canal for 1 minute. After 1 minute, it was transferred to a sterile test tube containing an anaerobic culture medium. The paper point was inserted into the medium and then placed directly into a refrigerator at $3-5^{\circ} \mathrm{C}$. Most samples were sent to the laboratory on the same day of sampling. If the sample was collected after the time that the laboratory accepted new cases for the day, it was kept in the refrigerator at $3-5{ }^{\circ} \mathrm{C}$ overnight and sent to the laboratory the next morning.

\subsection{Culture}

Once the Bacteriology Laboratory, of the Department of Veterinary Tropical Diseases, Faculty of Veterinary Science, University of Pretoria, received the samples the samples were processed according to a specific protocol:

The anaerobic samples were processed and cultured under anaerobic conditions in an anaerobic globe compartment. In the laboratory, paper points were plated onto plates containing pre-reduced Columbia agar containing $7 \%$ citrated horse blood agar $(\mathrm{CBA})^{\mathrm{d}}$, nonreduced $\mathrm{CBA}^{\mathrm{d}}$ and MacConkey agar $(\mathrm{MAC})^{\mathrm{d}}$. The paper points were then reinserted in the transport medium. All plates and the specimens in transport medium were incubated at $37^{\circ} \mathrm{C}$ for up to $72 \mathrm{~h}$. The pre-reduced CBA plates ${ }^{\mathrm{d}}$ being incubated under anaerobic conditions, the nonreduced $\mathrm{CBA}^{\mathrm{d}}$ in $5 \% \mathrm{CO}_{2}$ in air, and the MAC plates ${ }^{\mathrm{d}}$ and specimens in transport medium were incubated in room air. 
If growth was identified, a representative of each colony type was subcultured for purification and identified using phenotypic identification methods, including an in-house prepared test for Pasteurellaceae (Markey and others 2013). For other bacteria, commercial test kits were used: "Streptex streptococcal grouping"d API20S", API20NE" and API20A"

\subsection{Antibiotic sensitivity}

The Kirby-Bauer disk diffusion method (CLSI 2008) was used to determine antibiotic sensitivity of the isolates. This is a standardised method that is used to determine the resistance or sensitivity of fast growing aerobes or facultative anaerobes to specific antimicrobials in vitro, the results of which can be used by the clinician to select antibiotics to treat bacterial infections.

Five or more colonies of a 24-hour pure culture of the isolate of interest was touched with a sterile swab and suspended in $5 \mathrm{ml}$ normal saline to obtain a turbidity equal to 0.5 McFarland standard. A sterile swab was dipped in the suspension. The swab was streaked over the surface of the Mueller-Hinton agar $(\mathrm{MH})^{\mathrm{f}}$ in three directions to spead the suspension evenly. Mueller-Hinton agar with 5\% blood $^{\mathrm{f}}$ was used for bacteria that do not grow on $\mathrm{MH}$ agar. Commercial paper discs ${ }^{\mathrm{d}}$ containing specified amounts of antibacterial agents were placed on the inoculated agar surface (Quinn and others 2011, Markey and others 2013). The plates were incubated at $37^{\circ} \mathrm{C}$ in normal air. After 16-18 hours, the diameter of each zone of inhibition was measured in millimetres and the results compared with standards for interpretation of the zone size to classify each isolate as resistant, intermediate or sensitive to a particular antibiotic. In the case of Pasteurella multocida, agar plates were incubated at $37^{\circ} \mathrm{C}$ in $\mathrm{CO}_{2}$ for 20 to 24 hours before zones were measured (CLSI 2008, Quinn and others 1994, Markey and others 2013). 


\section{Results}

Twenty dogs were included in this study. The mean age was $4.6 \mathrm{yr}$ (range between 1 to $10 \mathrm{yr}$ ). A variety of dog breeds were included, namely Staffordshire Bull Terriers $20 \%$ (4/20), German Shepherd Dog 15\% (3/20), Rottweiler 10\% (2/20), Bull Mastiff 10\% (2/20), Boerboel 10\% (2/20), Cross-breed 10\% (2/20), Australian Shepherd Dog 5\% (1/20), Belgian Shepherd Dog 5\% (1/20), Boxer 5\% (1/20), English Bull Terrier 5\% (1/20) and Jack Russel Terrier 5\% (1/20). Of the 20 dogs included in this study, $70 \%(14 / 20)$ were intact males, 5\% $(1 / 20)$ were castrated males, $25 \%(5 / 20)$ were intact females. Fifteen dogs had one canine pulp sampled, two canine pulps were sampled from 4 dogs, and four canine pulps sampled from 1 dog. Pulp samples were obtained from 59.24\% (16/27) maxillary canine teeth and $40.76 \%$ (11/27) from mandibular canine teeth. There was no predilection for fracture of left or right canine tooth of the maxilla or mandible.

In our study, of the $27 \mathrm{RC}$ samples used, $92.59 \%$ were cultured positive, yielding a total of 49 cultivable isolates, belonging to 27 different microbial species and 18 different genera (Table 1). Individual RC yielded a maximum of 4 species each. Two RC had no cultivable bacteria. A single microorganism was found in nine RC. Ten RCs presented two species and 6 RCs had three or more species.

Of the bacterial isolates, $4.08 \%$ were strict anaerobes and $18.36 \%$ were aerobic. Facultative anaerobic bacteria accounted for the majority of the isolates $(77.56 \%)$. 
Table 1. Bacterial isolates from 27 pulps exposed due to complicated crown fractures in the canine teeth of dogs $(\mathrm{N}=49)$.

\begin{tabular}{|c|c|c|}
\hline & Isolat & isolates \\
\hline \multicolumn{3}{|l|}{$\frac{\text { Gram positive }}{\text { Facultative anaerobic }}$} \\
\hline Actinomyces spp. & 2 & $4,08 \%$ \\
\hline Bacillus spp. & 3 & $6,12 \%$ \\
\hline Bacillus cereus & 1 & $2,04 \%$ \\
\hline Corynebacterium spp. & 5 & $10,20 \%$ \\
\hline Corynebacterium spp. No 1 & 1 & $2,04 \%$ \\
\hline Corynebacterium spp. № 2 & 1 & $2,04 \%$ \\
\hline Enterococcus spp. & 2 & $4,08 \%$ \\
\hline Lactobacillus spp. & $\overline{1}$ & $2,04 \%$ \\
\hline Staphylococcus spp. & 1 & $2,04 \%$ \\
\hline Staphylococcus aureus & 1 & $2,04 \%$ \\
\hline \multicolumn{2}{|l|}{ Anaerobic } & $2,04 \%$ \\
\hline \multirow[t]{2}{*}{ Clostridium acetabulyticum } & 1 & $2,04 \%$ \\
\hline & 20 & $40,81 \%$ \\
\hline \multicolumn{3}{|l|}{ Gram negative } \\
\hline \multicolumn{3}{|l|}{ Aerobic } \\
\hline CDC group VE-2 & 1 & $2,04 \%$ \\
\hline Moraxella spp. & 4 & $8,17 \%$ \\
\hline Pseudomonas aeuroginosa & 3 & $6,12 \%$ \\
\hline \multicolumn{3}{|l|}{ Facultative Anaerobic } \\
\hline Aeromonas salmonicida & 3 & $6,12 \%$ \\
\hline Enteric group 8 & 1 & $2,04 \%$ \\
\hline Enterobacter cloacae & 1 & $2,04 \%$ \\
\hline Escherichia coli & 3 & $6,12 \%$ \\
\hline Pasteurella spp. & 2 & $4,08 \%$ \\
\hline Pasteurella canis & 1 & $2,04 \%$ \\
\hline Pasteurella multocida & 5 & $10,20 \%$ \\
\hline Pasteurella pneumotropica & 1 & $2,04 \%$ \\
\hline Proteus mirabilis & 1 & $2,04 \%$ \\
\hline Weeksella virosa & 1 & 2,04 \\
\hline \multicolumn{3}{|l|}{ Anaerobic } \\
\hline \multirow[t]{2}{*}{ Prevotella melalinogenica } & 1 & $2,04 \%$ \\
\hline & 29 & $59,19 \%$ \\
\hline Total isolates & 49 & $100 \%$ \\
\hline
\end{tabular}

Aerobic and facultative anaerobic bacteria were subjected to an antibiogram panel containing 14 different antimicrobials. Of all the antimicrobials tested, gentamicin (100\%) was the most- and lincomycin (15.21\%) was the least effective. The antimicrobial susceptibility of the aerobic and facultative anaerobic bacteria isolated from RCs with nonvital pulps is shown in Table 2. The antimicrobial efficacy on Lactobacillus spp. was not measured as it was not a rapid grower. 
Table 2. Antimicrobial in vitro efficacy against the aerobic and facultative anerobic cultivated bacteria from necrotic dog canine pulps $(\mathrm{N}=46)$.

\begin{tabular}{|c|c|c|c|}
\hline Antibiotics & R & I & S \\
\hline Amikacin & $10 / 46(21.73 \%)$ & $6 / 46(13.04 \%)$ & $30 / 46(65.23 \%)$ \\
\hline Amoxycillin / Ampicillin & $14 / 46(30.44 \%)$ & $14 / 46(30.44 \%)$ & $18 / 46(39.12 \%)$ \\
\hline Doxycycline / Oxitetracycline $^{*}$ & $6 / 46(13.04 \%)$ & $12 / 46(26.08 \%)$ & $28 / 46(60.88 \%)$ \\
\hline Enrofloxacin $^{*}$ & $3 / 45(6.84 \%)$ & $8 / 45(17.76 \%)$ & $34 / 45(75.56 \%)$ \\
\hline Gentamicin $^{\prime}$ Penicillin G & $0 / 46(0.00 \%)$ & $7 / 46(15.19 \%)$ & $39 / 46(84.81 \%)$ \\
\hline Sulpha / Trimethropim & $17 / 46(36.95 \%)$ & $16 / 46(34.78 \%)$ & $13 / 46(28.27 \%)$ \\
\hline Cephalothin / Lexin $^{*} 15 / 46(32.60 \%)$ & $2 / 46(4.34 \%)$ & $29 / 46(63.06 \%)$ \\
\hline Kanamycin $^{* *}$ & $17 / 46(36.95 \%)$ & $2 / 46(4.34 \%)$ & $27 / 46(58.71 \%)$ \\
\hline Lyncomycin $^{\text {Lincospectin }}$ & $7 / 44(15.89 \%)$ & $13 / 44(29.51 \%)$ & $24 / 44(54.60)$ \\
\hline Orbifloxacin $^{*}$ & $39 / 46(84.81 \%)$ & $3 / 46(6.51 \%)$ & $4 / 46(8.68 \%)$ \\
\hline Amoxycillin-Clavulanic Acid $^{* * *}$ & $28 / 46(60.88 \%)$ & $0 / 46(0.00 \%)$ & $18 / 46(39.12 \%)$ \\
\hline Tylosin Tartrate $^{*}$ & $7 / 39(17.39 \%)$ & $6 / 46(13.04 \%)$ & $32 / 46(69.57 \%)$ \\
\hline & $4 / 45(8.88 \%)$ & $4 / 39(10.25 \%)$ & $28 / 39(71.80 \%)$ \\
\hline
\end{tabular}

$* \mathrm{~N}=45$

$* * \mathrm{~N}=44$

$* * * \mathrm{~N}=39$

\section{Discussion}

Immediate clinical signs post CCF include pain, while those with delayed onset include facial swelling, tooth discoloration, and parulis. Some other signs are not visible clinically and are considered sequelae, like changes in the pulp: pulpitis (reversible or irreversible) and pulp necrosis. In the majority of cases, the condition is noticed following a visual inspection of the mouth. Problems with biting or a reduced willingness to bite (pain, lack of willingness to bite the target or biting it incompletely) have been reported in working dogs during the first weeks following CCF of canine teeth (Le Brench and others 1997). The ability of a dog to deliver a substantial bite is proportional to, amongst other things, the number of canine teeth the dog has (Le Brench and others 1997). In our study the incidence of CCF in the dogs was higher in younger individuals. The teeth of younger dogs have thinner dentinal walls, which may make them more at risk of fracturing. 
There are almost 800 distinct bacterial taxa recognised today as normal inhabitants of the oral cavity in humans (Paster and others 2006), although not all of them are present in the same individual at the same time. Half of them, to date, have been found to be uncultivable. Nevertheless, in humans only a small group of micro-organisms (258 distinct bacterial taxa) have been isolated and cultured from RCs (Siqueira and Rocas 2009). The integration of datasets from independent and dependent culture techniques published up to March 2008, revealed that 468 bacterial taxa have been found in human endodontic infections (Siqueira and Rocas 2009). Compared to human studies, very few bacterial species were recovered in this study. The authors suggest that the difference between the present study and human published data may be multifactorial. This may include the fact that no anaerobic environmental conditions were created in the oral cavity when sampling the RCs to ensure that the samples were transferred anaerobically to transport containers. These samples were not processed within a short period of time, sometimes taking up to 24h. Moreover, the use of only one paper point instead of three placed progressively for 60 seconds each (Ferreira and others 2006; Schirrmeister and others 2007) could have had an impact on the retrieval of bacteria from the RC. As the RC systems sampled in this study were longer than those of humans, the authors made use of paper points with a larger contact surface (ISO $25-60 \mathrm{~mm}$ ). The sample size may have played a role in the yield of bacteria; owing to the fact that there is a substantial oral bacterial diversity amongst different individuals (Siqueira and Rocas 2009). This postulate can be reinforced by the statement that although approximately 800 different taxa have been indentified in the oral cavity of humans, any particular individual can harbor about 100-200 of these recognised oral bacteria (Paster and others 2006). Thus, the larger the sample size, the more chances of obtaining more diverse results. The anatomical differences of large canine teeth compared to the teeth included in human endodontic studies may have contributed to sustaining aerobic conditions in the RCs. The fact that two root canals yielded 
no bacteria can be attributed most likely to the above hypothised study limitations. These two samples are clear outliers; therefore these two root canals should be treated following endodontic principles to prevent infection.

A maximum of 4 bacterial species were cultured from individual dog's RCs, representing less than half as many as have been cultured from human teeth (Gomes and others 1999; Haapasalo and others 1986). This is in keeping with the results published in dogs (with a maximum of 7 species per single RC (Ferreira and others 2006)), and cheetahs (with a maximum of 6 species (Almansa Ruiz and others 2016)). All the canine teeth examined in the present study had open RCs with nonvital pulps and thus it is likely the respective infections had been present for several weeks by the time the animals were presented. This change in the internal environment may have biased the yield of bacteria. This is in contrast with human studies, where pulps are sealed, inflamed and infected, but not yet necrotic. Microbial flora are far more diverse in acute dental infections as opposed to chronic infections that have been exposed to the oral fluids for some period of time (Melville and Birch 1967; Santos and others 2011).

Gram-negative strict anaerobic bacteria have been found to be the most prevalent microorganisms in primary endodontic infections in humans (Siqueira and Rocas 2009). In this study, Gram-negative facultative anaerobic isolates were the bacteria most commonly represented. The striking difference in the oxygen requirements of the bacteria isolated when open RCs versus sealed RCs were sampled has been statistically proven (Ferreira and others 2006), with a positive correlation between teeth that were sealed and the presence of strict anaerobes (Ferreira and others 2006). The low number of strict anaerobes that were isolated in this survey may have been the consequence of ecologic factors in the open canals, such as 
nutrient availability and oxygen concentration (Sundqvist 1992), the culture media or sampling technique used. The low number of strict anaerobes cultured corresponds with the results reported in open contaminated RCs of dog and cheetah teeth (Almansa Ruiz and others 2016; Ferreira and others 2006). A significant difference worth noting between the Ferreira $e t$ al 2006 study and this one is the teeth that were sampled. This study only used canine teeth, whereas Ferreira et al 2006 used second and fourth premolar teeth. Canine teeth have a much longer RC system than premolar teeth. Regardless of the anatomical differences, the incidence of anaerobic bacteria was comparable between the two studies. The main difference encountered between these two studies is the higher isolation of Gram positive bacterial species in open RCs, constituting up to $75.8 \%$ of all isolates; in contrast with the present study, where Gram positive bacteria were only represented by $40.81 \%$ of all isolates.

Bacterial species/phylotypes detected in the human literature fall into nine different phyla: Firmicutes, Bacteroidetes, Actinobacteria, Proteobacteria, Fusobacteria, Spirochaetes, Synergistes, TM7, and SRI (Siqueira and Rocas 2009). The taxa isolated in this study fall within four phyla, Actinobacteria, Firmicutes, Proteobacteria, and Bacteroidetes, with the Proteobacteria showing the greatest diversity. This is in contrast with the human literature, where Firmicutes is by far the most diverse group (Siqueira and Rocas 2009).

In the study performed by Ferreira et al. 2006, the results of those animals whose RC were constantly contaminated by saliva for 4 months, showed a higher isolation of facultative anaerobic and Gram positive genera, such as Streptococcus, Propionibacterium, and Staphylococcus. The human and dog oral cavity flora have some similarities; both comprise Gram positive cocci (mainly those of the genera Streptococcus, Micrococcus, Staphylococcus and Peptostreptococcus); Gram positive rods and filaments (Actinomyces and 
Propionibacterium); Gram negative cocci (Neisseria and Veillonella); and Gram negative rods (including the facultative anaerobic and capnophilic genera Haemophilus, Actinobacillus, Eikenella, and Capnocytophaga; and the obligate anaerobic genera Porphyromonas, Prevotella, and Fusobacterium) (Allaker and others 1992; Brook 1989; Goldstein 1992; Samaranayake 2002). The main notable difference in the oral microbial flora of humans versus dogs is the higher number of species detected in humans. This difference is due to the higher isolation rate of anaerobic bacteria in humans compared with animals (Brook 1989). Species from the genera Enterococcus (Goldstein 1992), Klebsiella, Escherichia, Citrobacter, Enterobacter (Kasempimolporn and others 2003), Clostridium and Bacillus spp. have been isolated from the oral cavity of dogs (Goldstein and others 1984). Clostridium spp., which are frequently isolated from the RCs of dogs (Ferreira and others 2006), are hardly found in human necrotic pulps when culture procedures are used (Gomes 1995). Furthermore, some species, such as Pasteurella spp, have been recovered from dogs but not from humans, especially P. multocida and P. fluorescens (Kasempimolporn and others 2003).

Since this study did not make use of an isolation device nor was crown disinfection performed prior to the sampling process, some of the bacteria isolated in this study may have been contaminants. However, as all the RCs sampled had been opened for unknown periods of time to the oral cavity (and therefore exposed to the oral flora) the authors believe that use of an isolation device would not have altered the microbial diversity.

All aerobic and facultative anaerobic bacterial species isolated in this study, with the exception of Lactobacillus spp., that was not a rapid grower, were tested in vitro against a panel of 14 antimicrobials using the Kirby-Bauer antibiotic testing or disk diffusion antibiotic 
sensitivity testing. This is the most complete described method for which interpretive standards have been developed and supported by clinical and laboratory data (Bonev and others 2008). This method was chosen due to its availability at the Bacteriology Laboratory, of the Department of Veterinary Tropical Diseases, Faculty of Veterinary Science, University of Pretoria and its relatively low cost. The main limitation of this technique is that it is not applicable to microorganisms that are fastidious, slow growing or have special growth requirements, such as the Lactobacillus spp. and anaerobic bacteria. This was taken into consideration when deciding on the appropriate method to evaluate the antimicrobial efficacy using previously published results as a reference (Almansa Ruiz and others 2016; Ferreira and others 2006) These studies showed a very low isolation rate of strict anaerobic bacteria. Another shortfall is the use of human clinical breakpoints for the interpretation of zone diameters where there is a lack of canine specific breakpoints which makes interpretation of clinical efficiency difficult.

The Kirby-Bauer disc diffusion method is a qualitative method that is carried out in vitro, thus does not take the various factors that may affect antibacterial activity in vivo into account (Quinn and others 2011). The results were dichotomized by classifying intermediate susceptibility as sensitive $[(\mathrm{S}+\mathrm{I}), \mathrm{R}]$. These inhibitory zone categories were converted to ordinal data. This step was necessary for comparison as the minimum inhibitory concentration (MIC) for each antimicrobial was not determined. The MIC is a much more costly and labour intensive method in comparison to the Kirby-Bauer disc diffusion method. However, it is a quantitave method, allowing the clinician not just to evaluate the efficacy of an antimicrobial but also to predict the tissue, blood or urine levels required to inhibit bacterial growth. The common way to dichotomise antibiogram results is to group resistance with intermediate, this was not the case in this study; the reason being that the antimicrobials are to be used 
intracanally, achieving very high concentrations on the area of interest, the RC. Hence, these results are not applicable for systemic use.

The antimicrobials with the highest efficacy in vitro were gentamicin and enrofloxacin. This is in contrast with the human literature where penicillin V (Baumgartner and Xia 2003), benzylpenicillin (penicillin G), amoxicillin/clavulanic acid, metronidazole, clindamycin (Baumgartner and Xia 2003; de Sousa and others 2003), amoxicillin, erythromycin, tetracycline (Lana and others 2001) and cephaclor (Jacinto and others 2003) were the antimicrobials demonstrating the highest efficacy in vitro. This difference on antimicrobial efficacy could be attributed to the higher isolation of strict anaerobic bacteria in human endodontics compare to the present study in dogs, where facultative anaerobic bacteria was the most commonly isolated. Bacteria isolated in this study were predominantly Gram negative, in continuity with human endodontics, but in contrast with a previous study performed in dogs by Ferreira (Ferreira and others 2006) where the most common bacteria were Gram negative. These bacteria were not tested for antimicrobial sensitivity thus no conclusions can be drawn from this comparison.

Anaerobic bacteria have intrinsic resistance to amynoglicosides because of the lack of oxidative metabolism to drive the intake of this antimicrobial (Giguere 2006). However this is not of great concern clinically owing to the fact that the isolation of anaerobic bacteria in this and previous studies (Ferreira and others 2006) is negligible.

Lang et al. 2016 showed a significant variation in antimicrobial resistance in vitro in those patients that received antimicrobial therapy prior to the sampling process compare to those that did not (Lang and others 2016). For patients to have been included in this study, 
they were not to have received antimicrobial therapy for at least 2 weeks prior to sample collection, hence the inability to compare the resistance of isolates if the patient did or did not receive antimicrobial therapy prior to sample collection. The vast majority of studies performed in human endodontics did not adopt exposure to antibiotic therapy as an exclusion criterion (Lang and others 2016). The resistance rate for tetracyclines in human endodontic infections is $64 \%$ of all isolates (Lang and others 2016), this is in contrast with the values obtained in this study or the data published in cheetah endodontics (Almansa Ruiz and others 2016), were the resistance rates were $13.4 \%$ and $18.51 \%$ respectively. The low efficacy of tetracyclines in human endodontics is probably a consequence of the intrinsic resistance among the anaerobic strains, as well as secondary resistance due to its broad use and misuse (Lang and others 2016). The lower resistance of isolates to tetracyclines in veterinary endodontics is perhaps due to the lower isolation rate of anaerobic microorganisms.

Antimicrobials have been considered as an adjunct to endodontic treatment for special circumstances (Mohammadi 2009b). They are reserved to treat infections that are likely to respond to them. Antibiotics can be used as an adjunct to endodontic treatment in a number of ways: locally, systemically and prophylactically (Mohammadi 2009b). The use of systemic antibiotics should be reserved for those patients with visible clinical signs like facial swelling, parulis, and elevated body temperature (Alexander 1997). The tendency towards indiscriminate antibiotic use should be discouraged. Preferably, susceptibility testing should be done when antibiotics are indicated. However, practioners tend to prescribe empiric antibiotics because the testing can take several days and even weeks when dealing with anaerobic bacteria, and in some instances many organisms present in the root canals are not cultivable. This empiric prescription is based on the knowledge of the endodontic microbiota 
(Mohammadi 2009b); hence the importance of this study to describe the endodontic microbiota and its sensitivity to a panel of commonly used antibiotics in veterinary practice

When the clinician is presented with a case with odontogenic infection, it is very important to distinguish between local or spreading systemic infections. If the immune system is not able to abate the advancing bacterial infection, the use of systemic antibiotics is indicated as a coadjuvant treatment to root canal therapy (Alexander 1997). In certain situations when the infection is localised to the endodontic system and the periradicular tissues, the use of systemic antibiotics will be considered negligent. Systemic antibiotics rely on the circulation to bring the active drug to an infected site that may no longer possess a normal blood supply, as it is in the case of teeth with nonvital pulps and its periradicular tissues; hence won't reach the source of bacterial infection (Mohammadi 2009a). Due to the ineffectiveness of systemic antibiotics in teeth with nonvital teeth and its periradicular tissues, the use of intra-canal antibiotics may be a more effective mode for delivery of antibiotics in the endodontic system (Mohammadi 2009a) and warrants further investigation in veterinary medicine.

\section{Conclusion}

The most common bacteria present in open root canals of dog's canine teeth were Gram negative facultative anaerobic bacteria. The most efficient antimicrobials in vitro against these bacteria were gentamicin and enrofloxacin. The use of systemic empiric antibiotics based on the results obtained in this study should be reserved for those patients that are inmunosuppresed or are showing signs of systemic spreading infections. The use of antibiotics locally will help deliver high concentration of the drug on the focus of the infection helping to control and maybe increase the success rate of root canal therapy. The use 
of antibiotics in endodontics must not be used as a substitute for root canal therapy but as a coadjuvant to control and treat infection present in dogs' canine teeth with nonvital pulps.

a. Dr. Shipp’s Dental and Specialty Products, 8361 W. Tangerine Rd. Marana, AZ (USA)

b. Baxter Healthcare Corporation. Wallingford Rd., Compton, Newbury, Berkshire (UK)

c. Carlo de Giorgi Srl, 1 Via Tonale, Boranzate, Milan (Italy)

d. Oxoid Products Ltd., Wade Road, Basingstoke, Hampshire, (UK)

e. API Systems, BioMérieux, 376 Chemnin de L’Orne, 69280 Marcy L’Etoile (France)

f. Selecta-MEDIA, BactLab House, 1 Abcon Close, 17 Hammer Avenue, Strijdompark, Johannesburg (RSA)

\section{References}

ALEXANDER, R. E. (1997) The appropiate use of antibiotics in dentistry - Basic principles of antibiotic therapy and prophylaxis. Quintessence Int, 815-828

ALLAKER, R. P., LLOYD, D. H. \& BAILEY, R. M. (1992) Population sizes and frequency of staphylococci at mucocutaneous sites on healthy dogs. Vet Rec 130, 303-304

ALMANSA RUIZ, J. C., BOSMAN, A. M. \& STEENKAMP, G. (2016) Bacterial Profile of Necrotic Pulps in Cheetah (Acinonyx Jubatus) Canine Teeth. J Zoo Wildl Med 47, 98-105

BAUMGARTNER, J. C. \& XIA, T. (2003) Antibiotic susceptibility of bacteria associated with endodontic abscesses. J Endod 29, 44-47

BONEV, B., HOOPER, J. \& PARISOT, J. (2008) Principles of assessing bacterial susceptibility to antibiotics using the agar diffusion method. J Antimicrob Chemother 61, $1295-1301$

BROOK, I. (1989) Human and animal bite infections. J Fam Pract 28, 713-718 
CLSI (2008) M100-S18 Performance Standards for Antimicrobial Susceptibility Testing. Wayne, Pennsylvania

DE SOUSA, E. L., FERRAZ, C. C., GOMES, B. P., PINHEIRO, E. T., TEIXEIRA, F. B. \& DE SOUZA-FILHO, F. J. (2003) Bacteriological study of root canals associated with periapical abscesses. Oral Surg Oral Med Oral Pathol Oral Radiol Endod 96, 332-339

FERREIRA, F. B., CAMPOS RABANG, H. R., PINHEIRO, E. T., GADE-NETO, C. R., ZAIA, A. A., FERRAZ, C. C., DE SOUZA-FILHO, F. J. \& GOMES, B. P. (2006) Root canal microbiota of dogs' teeth with periapical lesions induced by two different methods. Oral Surg Oral Med Oral Pathol Oral Radiol Endod 102, 564-570

GIGUERE, S. (2006) Antimicrobial Drug Action and Interaction: An Introduction. In Antimicrobial Therapy in Veterinary Medicine. Eds S. GIGUERE, J. F. PRESCOTT, J. D. BAGGOT, R. D. WALKER, P. M. DOWLING. Ames, Iowa, USA, Blackwell Publishing GOLDSTEIN, E. J. (1992) Bite wounds and infection. Clin Infect Dis 14, 633-638

GOLDSTEIN, E. J., CITRON, D. M. \& FINEGOLD, S. M. (1984) Role of anaerobic bacteria in bite-wound infections. Rev Infect Dis 6 Suppl 1, S177-183

GOMES, B. P. (1995) An investigation into the root canal microflora. Manchester, University Dental Hospital of Manchester

GOMES, B. P., DRUCKER, D. B. \& LILLEY, J. D. (1999) Endodontic microflora of different teeth in the same mouth. Anaerobe, 241-245

HAAPASALO, M., RANTA, H., RANTA, K. \& SHAH, H. (1986) Black-pigmented Bacteroides spp. in human apical periodontitis. Infect Immun 53, 149-153

HSIAO, W., LI, K., JONES, C., FRASER-LIGGETT, C. \& FOUAD, A. (2012) Microbial transformation from normal oral microbiota to acute endodontic infections. BMC Genomics JACINTO, R. C., GOMES, B. P., FERRAZ, C. C., ZAIA, A. A. \& FILHO, F. J. (2003) Microbiological analysis of infected root canals from symptomatic and asymptomatic teeth 
with periapical periodontitis and the antimicrobial susceptibility of some isolated anaerobic bacteria. Oral Microbiol Immunol 18, 285-292

KASEMPIMOLPORN， S., BENJAVONGKULCHAI， M., SAENGSEESOM， W. \& SITPRIJA, V. (2003) Oral bacterial flora of dogs with and without rabies: a preliminary study in Thailand. J Med Assoc Thai 86, 1162-1166

KUNTSI-VAATTOVAARA, H., VERSTRAETE, F. J. \& KASS, P. H. (2002) Results of root canal treatment in dogs: 127 cases (1995-2000). J Am Vet Med Assoc 220, 775-780

LANA, M. A., RIBEIRO-SOBRINHO, A. P., STEHLING, R., GARCIA, G. D., SILVA, B. K., HAMDAN, J. S., NICOLI, J. R., CARVALHO, M. A. \& FARIAS LDE, M. (2001) Microorganisms isolated from root canals presenting necrotic pulp and their drug susceptibility in vitro. Oral Microbiol Immunol 16, 100-105

LANG, P. M., JACINTO, R. C., DAL PIZZOL, T. S., FERREIRA, M. B. \& MONTAGNER, F. (2016) Resistance profiles to antimicrobial agents in bacteria isolated from acute endodontic infections: systematic review and meta-analysis. Int J Antimicrob Agents 48, 467474

LE BRENCH, C., HAMEL, L., LE NIHOUANNEN, J. C. \& DACULSI, G. (1997) Epidemiological study of canine teeth fractures in military dogs. Journal of Veterinary Dentistry $14,51-55$

MARKEY, B., LEONARD, F., ARCHAMBAULT, M., CULLINANE, A. \& MAGUIRE, D. Eds (2013) Clinical Veterinary Microbiology. London, UK, Mosby Ltd.

MARSH, P. D. (2003) Are dental diseases examples of ecological catastrophes? Microbiology 149, 279-294

MELVILLE, T. H. \& BIRCH, R. H. (1967) Root canal and periapical floras of infected teeth. Oral Surg Oral Med Oral Pathol 23, 93-98 
MOHAMMADI, Z. (2009a) Systemic and local applications of steroids in endodontics: an update review. Int Dent J 59, 297-304

MOHAMMADI, Z. (2009b) Systemic, prophylactic and local applications of antimicrobials in endodontics: an update review. Int Dent J 59, 175-186

MOLVEN, O. \& HALSE, A. (1988) Success rates for gutta-percha and Kloroperka N-0 root fillings made by undergraduate students: radiographic findings after 10-17 years. Int Endod J $21,243-250$

NAIR, P. N., SJOGREN, U., KREY, G., KAHNBERG, K. E. \& SUNDQVIST, G. (1990) Intraradicular bacteria and fungi in root-filled, asymptomatic human teeth with therapyresistant periapical lesions: a long-term light and electron microscopic follow-up study. J Endod 16, 580-588

PASTER, B. J., OLSEN, I., AAS, J. A. \& DEWHIRST, F. E. (2006) The breadth of bacterial diversity in the human periodontal pocket and other oral sites. Periodontol 2000 42, 80-87

PETERS, O. A. \& PETERS, C. I. (2011) Cleaning and Shaping of the the root canal system. In Pathways of the pulp. 10th ed. edn. Eds K. M. HARGREAVES, S. COHEN. St. Louis (MO), Mosby Elsevier. pp p. 283-348

PRESHAW, P. M., SEYMOUR, R. A. \& HEASMAN, P. A. (2004) Current concepts in periodontal pathogenesis. Dental Update 31

QUINN, P. J., MARKEY, B. K., LEONARD, F. C., FITZPATRICK, E. S., FANNING, S. \& HARTIGAN, P. J. (2011) Veterinary Microbiology and Microbial Disease. Chichester, West Sussex, UK, Wiley-Blackwell

SAMARANAYAKE, L. P. (2002) Normal oral flora, the oral ecosystem and dental plaque. In Essential microbiology for dentistry. Ed L. P. SAMARANAYAKE. London, Harcourt Publishers Limited. pp 207-213 
SANTOS, A. L., SIQUEIRA, J. F., JR., ROCAS, I. N., JESUS, E. C., ROSADO, A. S. \& TIEDJE, J. M. (2011) Comparing the bacterial diversity of acute and chronic dental root canal infections. PLoS One 6, e28088

SCHIRRMEISTER, J. F., LIEBENOW, A. L., BRAUN, G., WITTMER, A., HELLWIG, E. \& AL-AHMAD, A. (2007) Detection and eradication of microorganisms in root-filled teeth associated with periradicular lesions: an in vivo study. J Endod 33, 536-540

SIGURDSSON, A., TROPE, M. \& CHIVIAN, N. (2011) The role of endodontics after dental traumatic injuries. In Pathways of the pulp. Eds K. M. HARGREAVES, S. COHEN. St. Louis (MO), Mosby Elsevier. pp 620-654

SIQUEIRA, J. F., JR. \& ROCAS, I. N. (2008) Clinical implications and microbiology of bacterial persistence after treatment procedures. J Endod 34, 1291-1301 e1293

SIQUEIRA, J. F., JR. \& ROCAS, I. N. (2009) Diversity of endodontic microbiota revisited. J Dent Res 88, 969-981

SJOGREN, U., HAGGLUND, B., SUNDQVIST, G. \& WING, K. (1990) Factors affecting the long-term results of endodontic treatment. J Endod 16, 498-504 SUNDQVIST, G. (1992) Ecology of the root canal flora. J Endod 18, 427-430

SUNDQVIST, G., FIGDOR, D., PERSSON, S. \& SJOGREN, U. (1998) Microbiologic analysis of teeth with failed endodontic treatment and the outcome of conservative retreatment. Oral Surg Oral Med Oral Pathol Oral Radiol Endod 85, 86-93

YOSHIDA, M., FUKUSHIMA, H., YAMAMOTO, K., OGAWA, K., TODA, T. \& SAGAWA, H. (1987) Correlation between clinical symptoms and microorganisms isolated from root canals of teeth with periapical pathosis. J Endod 13, 24-28 